\title{
O MODELO DE DESENVOLVIMENTO SUSTENTÁ VEL PROMOVIDO PELA AGRICULTURA FAMILIAR EM FUNÇÃO DA PRESERVAÇÃO DO MEIO AMBIENTE.
}

\section{DEVELOPMENT MODEL SUSTAINABLE PROMOTED BY THE FAMILY AGRICULTURE IN FUNCTION OF ENVIRONMENTAL PRESERVATION}

\author{
${ }^{1}$ Sônia Maria Agra Zamith \\ ${ }^{2}$ Mário César de Queiroz Albuquerque
}

\section{RESUMO}

O objetivo da pesquisa é indicar direcionamentos de alternativas ao desenvolvimento autossustentável delineado no princípio de um contexto socioeconômico familiar, e de sustentabilidade, na proteção ao meio ambiente promovida pela agricultura familiar. A inserção do modelo de agricultura familiar na discussão, parte da verificação preliminar do modo de produção agrícola utilizado por unidades familiares, ao tempo em que garante a subsistência e permite a comercialização dos níveis excedentes de produção. O método empregado foi o hipotético-dedutivo, com finalidade explicativa, cujos meios corresponderam à seleção de autores que deram o suporte necessário ao entendimento do princípio da prevenção em direito ambiental.

Palavras-chave: Prevenção ambiental, Desenvolvimento sustentável, Sustentabilidade, Agricultura familiar

\begin{abstract}
The objective of the research is to indicate directions of alternatives to self-sustainable development outlined at the principle of a family socioeconomic context, and sustainability, environmental protection promoted by family agriculture. The inclusion of Family agriculture model in the discussion, of the preliminary verification of the agricultural production methods used by family units at the time ensuring the livelihood and allows the marketing of surplus production levels. The method employed was the hypotheticaldeductive, with explanatory purpose, which means corresponded to the selection of authors who have the necessary support to the understanding of the precautionary principle in environmental law.
\end{abstract}

Keywords: Environmental prevention, Sustainable development, Sustainability, Family agriculture

\footnotetext{
${ }^{1}$ Mestranda na Universidade Estadual do Amazonas - UEA, Amazonas (Brasil) em Direito Ambiental e mestranda em Ciência e Meio Ambiente pela Universidade Federal do Pará - UFPA, Pará (Brasil). Professora do Instituto Universitário de Ensino Superior do Amazonas - CIESA, Amazonas (Brasil). E-mail: szam3@ @lubedorei.com.br ${ }^{2}$ Mestrando do curso de Sociologia pela Universidade Federal do Amazonas - UFAM, Amazonas (Brasil). E-mail: mcqualy@gmail.com
} 


\section{INTRODUÇÃO}

Hodiernamente, o tema "agricultura familiar" vem ganhando contornos de legitimidade social, política, acadêmica, e no prisma de uma reformulação a um modelo de desenvolvimento de economia verde fundamentado em um uso racional, sustentável e adequado dos recursos naturais, que são finitos. A partir da década de 1990, a expressão veio a consolidar o modelo agrícola predominante em boa parte do país, surgida com o advento de movimentos sociais originados da necessidade de estabelecimento de políticas para reverter o quadro de instabilidade agrícola promovido pelo alarde de agricultores em busca de espaço para assentamentos e arrendamentos agrícolas.

Com a criação do Programa Nacional de Fortalecimento da Agricultura Familiar (PRONAF), viabilizado pelo Decreto $\mathrm{n}^{\circ} 1.946$, de 28/06/96, propiciou ao conceito da agricultura familiar a se solidificar no cenário sociopolítico brasileiro, sendo legitimada como um instrumento de conquista do movimento sindical rural, agente facilitador para gerar aumento da capacidade de renda e da geração de empregos e produtividade da agricultura familiar. Pequenos produtores rurais, alijados do contexto de políticas públicas em períodos passados e com inúmeras dificuldades em se manter na atividade rural, passaram a ser contemplados com o alcance do Estado na aplicação de estratégias como menores taxas de juros, apoio institucional e técnico (BRASIL, 1996; MATTEI, 2015).

Consolidada como uma atividade que representa um ganho social considerável, a agricultura familiar passou, há pouco tempo, a incorporar outros modelos: o de sustentabilidade e o de desenvolvimento sustentável. Ainda que ações e estudos tímidos não fortaleçam essa visão, é possível observar que algumas ações estão sendo direcionadas para que essa característica seja uma das principais peças na engrenagem do modelo de agricultura familiar.

Deriva dessa abordagem a problemática norteadora do presente estudo, a saber: é possível considerar a agricultura familiar como uma proposta de desenvolvimento sustentável, em função do apelo de proteção ao meio ambiente?

O objetivo geral da presente pesquisa foi de apontar direcionamentos que sustentem a proposta de desenvolvimento sustentável e de sustentabilidade, a partir da proteção ao meio ambiente promovida pela agricultura familiar.

O percurso metodológico utilizado para sua consecução envolveu a definição pelo método hipotético-dedutivo, com finalidade explicativa, cujos meios envolveram a busca pela 
teorização sobre o princípio da prevenção no direito ambiental, a análise conceitual dos termos sustentabilidade e desenvolvimento sustentável, e a inserção da agricultura familiar nesses contextos.

De cunho eminentemente bibliográfico, seus resultados foram alcançados por meio de uma seleção literária específica sobre os assuntos elencados, com base na análise de conteúdo para as categorias apresentadas.

\section{O PRINCÍPIO DA PREVENÇÃO NO DIREITO AMBIENTAL}

O Direito Ambiental representa uma ciência jurídica de recente origem, mas que, no entanto, encontra esparsa legislação no que diz respeito à proteção do meio ambiente, utilizando-se de instrumentos jurídicos a fim de propiciar um melhor reflexo à melhor qualidade de vida à sociedade.

Entre os princípios norteadores que fundamentam o ordenamento jurídico nacional do direito ambiental, o da prevenção do dano ambiental é um dos mais discutidos, e consiste na aplicação de mecanismos e ações voltadas para o afastamento do risco ambiental. Trata-se, por caracterização, de uma antecipação de medidas com vistas a evitar as agressões ambientais ou, como enseja Farias (2006, p. 3), "a prevenção é mais importante do que a responsabilização do dano ambiental".

Sua origem remonta ao contido no art. 225, caput, da Constituição brasileira de 1988 , onde se destaca que:

Todos têm direito ao meio ambiente ecologicamente equilibrado, bem de uso comum do povo e essencial à sadia qualidade de vida, impondo-se ao poder público e à coletividade o dever de defendê-lo e preservá-lo para as presentes e futuras gerações (BRASIL, 1988).

Em relação a prevenção, cuja ideia de proteção já está implícita, pode-se considerar sua relevância quando se remete a presunção de que, na hipótese de ocorrer o dano ambiental, é praticamente impossível exercer a reconstituição ambiental, pela perda significativa de elementos do ecossistema e da biodiversidade.

A prevenção ambiental para se sustentar, necessita do prévio conhecimento em relação aos danos que determinada situação e/ou condição pode proporcionar ao bem ambiental, e quais providências são necessárias para evitar seu acontecimento.

O sistema normativo brasileiro, em sede de tutela ambiental, já prevê o licenciamento ambiental com a realização prévia de estudos de impacto ambiental, de tombamento e de 
sanções administrativas. Especificamente nessas circunstâncias, o direito ambiental faculta ao Estado a imposição de multas ao agente poluidor.

Nas premissas que envolvem o direito ambiental, é possível detectar três esferas básicas de atuação, quais sejam: a preventiva, a reparatória e a repressiva. Nos dizeres de Freitas (2003, p. 254),
A preventiva está voltada para o momento anterior a consumação do dano, ou seja, o mero risco, atendendo ao objetivo fundamental do direito ambiental. Importante aqui ressaltar que na prevenção ocorre ação inibitória, enquanto que nas demais, a reparatória e a repressiva, se limitam a tratar do dano já causado, que é quase sempre incerto, de difícil reparação e custoso.

Consolidado como um marco para o Brasil, a Lei $\mathrm{n}^{\circ}$ 6.938/1981 instituiu a responsabilidade objetiva em matéria ambiental, fundamentalmente no artigo 14 , parágrafo $1^{\circ}$, da citada lei. Este dispositivo legal rompeu com o paradigma tradicional individualista, porque objetivou a responsabilidade civil por danos ambientais, não mais empregando o art. 159 do Código Civil de 1916, que hoje encontra-se revogado pela Lei 10.406/2002, que inseriu o Novo Código Civil Brasileiro (BRASIL, 1981; 2002).

No vernáculo de Benjamin (1998, p. 85), o direito ambiental nacional, a partir da Lei $\mathrm{n}^{\mathrm{o}}$ 6.938/1981, passou a proteger o individual a partir do coletivo. Daí sua natureza essencialmente pública. Portanto, a exigência de reparação do poluidor à vítima do dano ambiental, restará caracterizada pela atividade do agente e o nexo de causalidade com o dano ambiental, não mais se exigindo a culpabilidade deste agente.

A Constituição Federal de 1988 incorporou a responsabilidade objetiva ambiental proclamada pela legislação ordinária ao mencionar no parágrafo $3^{\circ}$ do seu artigo 225 , que as condutas e atividades consideradas lesivas ao meio ambiente sujeitarão os degradadores a reparar os danos causados, não fazendo qualquer menção da existência de culpa na atuação do agente degradador, quando estipula: " $\$ 3^{\circ}$ As condutas e atividades consideradas lesivas ao meio ambiente sujeitarão os infratores, pessoas físicas ou jurídicas, a sanções penais e administrativas, independentemente da obrigação de reparar os danos causados" (BRASIL, 1988).

Nesta via, o artigo 927, parágrafo único da Lei $\mathrm{n}^{\circ}$ 10.406/2002, (o novo Código Civil Brasileiro) estabelece a obrigação de reparar o dano, independentemente de culpa, fica obrigado de repará-lo em lei, ou quando a atividade normalmente desenvolvida pelo autor do dano implicar, por sua natureza, risco para os direitos de outrem, conforme esculpido abaixo: 
Art. 927. Aquele que, por ato ilícito (arts. 186 e 187), causar dano a outrem, fica obrigado a repará-lo.

Parágrafo único. Haverá obrigação de reparar o dano, independentemente de culpa, nos casos especificados em lei, ou quando a atividade normalmente desenvolvida pelo autor do dano implicar, por sua natureza, risco para os direitos de outrem (BRASIL, 2002).

O dano ambiental como se constitui de natureza difusa, reverbera em comunidade, não podendo determiná-las ou ainda atingir a o ambiente natural sem definir os possíveis ecossistemas atingidos e consequências determináveis. É desta forma, pela natureza difusa do dano ambiental, o fundamento complementar da responsabilidade civil ambiental objetiva. Além do risco proveniente da atividade, a característica difusa da natureza corrobora a aplicação da responsabilidade objetiva em matéria ambiental.

Neste sentido, havendo uma atividade que cause dano difuso ambiental, necessária se faz a responsabilização pelo risco ambiental proveniente desta atividade, não se perquirindo se a atividade estava isenta de culpa ou se estava acobertada por excludentes de força maior ou estado de necessidade (MACHADO, 2001).

Pelo sistema adotado no Direito Ambiental Brasileiro não se discute, necessariamente, a legalidade do ato. É a potencialidade de dano que o ato possa trazer aos bens ambientais que servirá de fundamento para a responsabilização, desta forma, não exonera o poluidor ou degradador a prova de que sua atividade é normal e lícita, de acordo com as técnicas mais apuradas. O que se leva em conta, quanto à responsabilidade objetiva, é a doutrina da normalidade da causa e anormalidade do resultado.

Nesse sentido, o princípio da prevenção ambiental corresponde à aplicação de prévia avaliação quanto aos impactos ambientais decorrentes da atividade humana de qualquer natureza. Também denominado de princípio da cautela prudência, é considerado, hodiernamente, como um dos mais relevantes no que tange à proteção jurídica do meio ambiente.

Na Constituição Federal de 1988, mais precisamente em seu art. 225, pode-se constatar a essência do princípio da prevenção, quando alude que o Poder Público tem a obrigação de assegurar o direito ao meio ambiente de forma ecologicamente equilibrada (BRASIL, 1988).

Em seara de legislação infraconstitucional, verifica-se a Lei no 6.938/1981 como a que criou a Política Nacional do Meio Ambiente, e que estabelece a necessidade da avaliação de impactos ambientais, característica norteadora do princípio da prevenção. 
A Declaração do Rio sobre Meio Ambiente e Desenvolvimento de 1992 destaca a precaução ambiental nos seus princípios 15 e 17, respectivamente:

Princípio 15. Com o fim de proteger o meio ambiente, o princípio da precaução deverá ser amplamente observado pelos Estados, de acordo com suas capacidades. Quando houver ameaça de danos graves ou irreversíveis, a ausência de certeza científica absoluta não será utilizada como razão para o adiamento de medidas economicamente viáveis para prevenir a degradação ambiental.

Princípio 17: A avaliação do impacto ambiental, como instrumento nacional, será efetuada para as atividades planejadas que possam vir a ter um impacto adverso significativo sobre o meio ambiente e estejam sujeitas à decisão de uma autoridade nacional competente (RAMID e RIBEIRO, 1992, p. 157).

Na concepção de Mirra (1996, p. 185), não é possível para a ciência oferecer uma certeza em relação às medidas que devem ser tomadas para evitar consequências danosas ao meio ambiente, “[...] pois algo que hoje é considerado inofensivo pode ser no futuro perigoso e vice-versa". Portanto, a prevenção caracteriza-se pela ação antecipada diante do risco ou do perigo.

O objetivo deste princípio não é imobilizar as atividades humanas e sim conservar a qualidade de vida e a natureza existente no planeta para as presentes e futuras gerações.

Este princípio pode ser identificado também no preceito contido no inciso VI do artigo 170 da $\mathrm{CF}$, onde se estabelece que a ordem econômica deve observar o princípio de defesa do meio ambiente, entre outros, existindo assim um dever jurídico constitucional de considerar o meio ambiente no momento da implantação de qualquer empreendimento econômico (BRASIL, 1988).

Judicialmente já se tem obtido o reconhecimento de que, na incerteza, não se deve praticar o ato ou permitir o uso ou produção de determinadas substâncias. Conclui-se, então, que este princípio é primordial, visto que não autoriza que sejam feitas intervenções no meio ambiente antes de efetiva comprovação de que estas não serão prejudiciais (DAMACENA, 2009, p. 2).

Quanto ao princípio da prevenção, o artigo 225, caput, da Constituição Federal, impõe ao Poder Público e a coletividade o dever de defender e preservar o meio ambiente para as presentes e futuras gerações. É deste dever de preservação que decorre este princípio.

Os danos causados ao meio ambiente são extremamente difíceis de serem reparados, e essa reparação, quando possível, possui um custo muito elevado. Desta forma surge a importância de uma atuação preventiva para evitar as degradações ambientais.

De acordo com este princípio, sempre que houver perigo de ocorrência de um dano grave ou irreversível, a falta de certeza científica absoluta não deverá ser utilizada como 
razão para se adiar a adoção de medidas eficazes para impedir a degradação do meio ambiente, sobretudo em função dos custos dessas medidas, ou seja, se existirem dúvidas no meio científico sobre os danos que determinada atividade possa causar ao meio ambiente, esta deve ser evitada ou rigorosamente controlada, pois no futuro, quando se puder determinar com certeza os prejuízos desta atividade, os danos já existirão e não poderão ser reparados.

São instrumentos de aplicação deste princípio o estudo prévio de impacto ambiental, o manejo ecológico, o tombamento, as liminares, as sanções administrativas, entre outras. Deve-se destacar também a importância da consciência ecológica, desenvolvida através de uma política de educação ambiental, e dos incentivos fiscais e benefícios proporcionados a atividades que atuem em parceria com o meio ambiente.

\section{A AGRICULTURA FAMILIAR: CONTEXTO INTRODUTÓRIO}

Também chamada de "agricultura de vizinhança", a agricultura familiar representa uma atividade econômica e produtiva, onde descortina-se uma troca de experiências entre pequenos produtores no plantio, cultivo e comercialização de produtos agrícolas. Seu envolvimento com o desenvolvimento sustentável e a preservação do meio ambiente é caracterizado por meio de boas práticas de agricultura, onde essa troca de experiências permite a perpetuação do empreendimento ou estabelecimento, aliado à preservação ambiental.

A agricultura familiar, no Brasil, é sustentada juridicamente pela Política Nacional da Agricultura Familiar e Empreendimentos Familiares, sob a égide da Lei $n^{\circ} 11.326 / 2006$. O mesmo dispositivo, em seu art. $3^{\circ}$, conceitua como agricultor familiar e empreendedor familiar rural o indivíduo que pratica atividades no meio rural, e que atenda, de forma simultânea, aos seguintes critérios: não deter, a qualquer título, área maior do que quatro módulos fiscais; utilizar predominantemente, nas atividades econômicas de seu estabelecimento ou empreendimento, mão de obra oriunda do próprio núcleo familiar; deter percentual mínimo de sua renda familiar oriunda de suas atividades econômicas; e dirigir seu estabelecimento ou empreendimento juntamente com sua família (BRASIL, 2006).

$\mathrm{Na}$ explicação de Lehfeld et al. (2014), a agricultura familiar é uma atividade econômica que, para muitos autores, possui importância significativa na economia e na preservação ambiental, podendo ser considerada, também como instrumento de viabilização do Estado de Direito Ambiental, ao se conjugar o dever social juntamente com a racionalidade 
jurídica na recuperação e preservação ambiental, ao mesmo tempo em que se viabiliza uma atividade econômica que atende a uma determinada classe igualmente importante dentro do cenário econômico nacional.

Pode-se concordar com Reis (2008), quando afirma que a agricultura familiar detém uma função social, notadamente quando se articula com a função social e ambiental da propriedade. Nesses termos, merece proteção, fomento e compatibilização com a proteção ambiental, já que permite a subsistência de um número considerável de famílias aliado a um sistema de boas práticas que coincidem com a preservação ambiental.

No âmbito dessa questão, a tutela ambiental se vincula à política agrícola, já que, hodiernamente, contratos de caráter agrário não podem se desvincular da preservação ambiental, submetendo-se o agricultor familiar, por esse mister, a restrições e limites jurídicos, econômicos e políticos, mas acima de tudo representando uma função socioambiental e de promoção do desenvolvimento sustentável (LEHFELD et al., 2014).

Em se tratando de boas práticas, Coutinho (2011) destaca que a agricultura familiar também desponta como um aspecto de sustentabilidade, já que se vale da utilização racional dos recursos naturais em seu processo produtivo. Via de regra, sua produção dispensa ou utiliza de forma mínima o uso de agrotóxicos, e sua produção é escoada de modo a evitar a perda de produtos.

Refere também Wanderley (2011) que a agricultura familiar não é novidade no campo das categorias sociais nem tampouco no âmbito da sociologia rural. Entretanto, no cenário brasileiro, somente nos últimos anos seu significado, abrangência e utilização tem se destacado enquanto alternativas de renovação e novidade no campo do desenvolvimento sustentável.

A população brasileira consome cerca de $60 \%$ de alimentos produzidos pelas cerca de quatro milhões de pequenas propriedades rurais. Estas ainda empregam $80 \%$ da mão de obra disponível no segmento rural do país. Disputa a atenção do Poder Público em pé de igualdade com o agronegócio exportador, no que diz respeito ao reconhecimento de sua parcela de contribuição para o desenvolvimento econômico e financeiro do país (SEBRAE, 2014; DELGADO, 2012).

Para Oliveira et al. (2015), é um segmento de alta produtividade, onde a produção se dá por meio da integração entre trabalho e gestão, afinal, são os próprios agricultores os responsáveis pelo direcionamento do processo produtivo. 
Sua relevância pode ser identificada pela presença da temática em amplos debates e discussões onde a sustentabilidade ambiental se faz presente, aliado ao conceito de geração de emprego e renda. Indicadores mostrados por Fauth (2006) dão conta de que a agricultura familiar sustenta $97 \%$ do fumo, $84 \%$ da mandioca, $67 \%$ do feijão, $59 \%$ da suinocultura, $52 \%$ do leite, $49 \%$ do milho, $40 \%$ de aves, $32 \%$ da soja e $25 \%$ do café produzidos nacionalmente.

\section{A AGRICULTURA FAMILIAR: SUSTENTABILIDADE OU DESENVOLVIMENTO SUSTENTÁVEL?}

Tratar do tema sustentabilidade implica também em abordar sobre o desenvolvimento sustentável. Apesar de formarem conceitos, indicadores e parâmetros diferenciados, se inserem na mesma ordem, quando se referem a questões ambientais.

O desenvolvimento sustentável é referido como aquele que é capaz de suprir as necessidades da geração atual, sem comprometer a capacidade de atender as necessidades das futuras gerações, no conceito trazido pela Comissão Mundial para o Meio Ambiente e o Desenvolvimento (CMMAD).

Segundo especialistas como Romeiro (1998), para ser considerado sustentável, o desenvolvimento deve ser economicamente eficiente, ecologicamente viável e socialmente desejável.

O conceito de desenvolvimento sustentável não é simplesmente um modismo intelectual do final do século XX, senão fruto da consciência dos graves problemas ambientais e socioeconômicos que a humanidade vem enfrentando. As sociedades e nações do mundo em pleno processo de globalização e integração socioeconômicas estão percebendo claramente os limites dos recursos naturais do planeta. Mais ainda, os princípios e as maneiras em que esta integração mundial ocorre produzem efeitos colaterais desastrosos, tais como impactos ambientais de dimensões planetárias, níveis de injustiça social crescentes e uma voracidade desenfreada em relação aos recursos naturais. A percepção dessas limitações do modelo econômico globalizado traz consequências profundas na maneira de encarar o futuro da humanidade.

Assim, desenvolvimento sustentável pode ser considerado de certa maneira um contra conceito, na medida em que surge como antítese a um desenvolvimento econômico e social do planeta que é percebido como insustentável.

As dificuldades em torno desse conceito se devem ao grande número de pontos de vista, do alto nível de abstração e da falta de elementos operacionais capazes de medir 
concretamente a sustentabilidade de um processo de desenvolvimento. Em outras palavras: é preciso construir uma ciência inovadora para a sociedade sustentável.

A prática sustentável se alia a aspectos sociais, econômicos e ambientais que não podem ser entendidos separadamente. No meio agrícola, pode-se concordar com a opinião de Ehlers (1998), quando afirma que os objetivos do desenvolvimento sustentável nessa seara correspondem a: manutenção dos recursos naturais e da produtividade agrícola por longo prazo; dimensões mínimas de impactos nocivos ao meio ambiente; adequados retornos aos produtores; otimização da produção com a utilização mínima de insumos externos; satisfação das necessidades humanas de renda e alimentos; atendimento das necessidades sociais das famílias e das comunidades rurais.

A Organização das Nações Unidas para a Alimentação e Agricultura (FAO) também contribui, destacando a necessidade de implementação de políticas científicas e tecnológicas em sistemas que integram agricultura e pecuária, em produtos tradicionais e naqueles que dependem de muita mão de obra (CRUZ, 2012).

Quanto ao conceito de sustentabilidade, tem-se a explicação de Cavalcanti (1998), de que se trata de uma possibilidade de obtenção de condições contínuas sucessivas ou superiores de vida para determinado grupo de pessoas e seus sucessores em um determinado ecossistema.

A sustentabilidade, em seu viés ambiental, liga-se à preservação ou aprimoramento da base produtiva de recursos, devidamente complementada pela sustentabilidade social, o que implica na condição de dignidade e qualidade de vida para as populações.

Para a agricultura familiar, a ideia de sustentabilidade se associa ao do desenvolvimento sustentável, na medida em que as técnicas da moderna agricultura não correspondem aos anseios populacionais de produção agrícola conjugada com a prevenção do meio ambiente e preservação dos recursos naturais. Além disso, a busca por alimentação mais saudável representa um nicho de pressão social que valoriza a agricultura que não agride o meio ambiente.

A agricultura sustentável, por conseguinte, impele as populações a reverem os tradicionais conceitos de agricultura de baixa renda, com produção em pequena escala e foco na subsistência. A agricultura familiar, por sua adesão a esse modelo, pode ser considerada como uma alternativa onde a qualidade do processo produtivo está assegurado pelo modelo de gestão familiar, independentemente do nível de capacidade de geração de renda. 
Em termos de prevenção ao meio ambiente, soma-se o caráter de sustentabilidade promovido pela agricultura familiar ao fator de maior eficiência aplicado ao sistema de produção agrícola que, nesse caso, se confunde com a realidade ecológica vivenciada por cada unidade familiar detentora de propriedade rural.

Conforme pontua Gomes (2004), o sistema de produção, no âmbito das unidades familiares que compõem o escopo da agricultura familiar sustentável, implica na obediência aos seguintes requisitos: redução do uso de energia e recursos; redução das perdas de nutrientes e melhora dos atuais com o uso renovável de nutrientes a partir do plantio de leguminosas, da adubação orgânica e outros mecanismos eficientes de reciclagem; incentivo à produção local de cultivos adaptados ao meio natural e socioeconômico; minimização da degradação do solo; redução de custos e aumento da eficiência, favorecendo a viabilidade econômica dos estabelecimentos e dos empreendimentos de agricultura familiar.

\section{A Agricultura FAMILIAR E A PREVENÇÃO AO MEIO AMBIENTE}

Ao nível de prevenção ao meio ambiente, a agricultura familiar ainda desponta como controversa no cenário nacional. Ainda hoje perdura a evidência empírica de que a grande maioria dos assentamentos voltados para a agricultura familiar serve apenas para subsistência com leve associação para a produção comercial.

Outros críticos do sistema de agricultura familiar, como Buainain et al. (2003) e Germer (2014) apontam que a produção gerada pela agricultura familiar é insuficiente para que essa denominação seja procedente, apesar de que, em muitos momentos históricos da nação brasileira, tal modelo tenha se mostrado relevante, mormente na condição da formação agrária do país.

Para Rosa (1999, p. 3), a viabilização do empreendimento agrário depende e muito do tamanho da área cultivada, de equipamentos agrícolas e da mão de obra utilizada e, tendo em vista a escala de produção agrícola determinada pelo momento pós-modernização que vem causando impactos significativos na oferta da mão de obra e na intensidade do uso da terra, pode-se conceber que a categoria do pequeno produtor - característica bem marcante no contexto da agricultura familiar - vem perdendo sua importância e não atingindo, em nível de escala, uma diversidade que possa considerar o empreendimento e/ou o estabelecimento como sustentável, ainda que os números mostrados em tópico anterior sinalizem positivamente para isso. 
Pode-se considerar, com base na elucidação trazida pela autora supracitada, que, em termos de prevenção a danos causados ao meio ambiente, esse tipo de iniciativa privada tenha, realmente, alcançado a condição de ser um empreendimento sustentável, mas em termos de desenvolvimento sustentável, essa iniciativa não se configura como um empreendimento, haja vista que a produção agrícola gerada por essas áreas é considerada pequena para a necessidade de abastecimento observada no cenário nacional. Ademais, o tamanho da área é desproporcional ao tamanho do investimento em capital e mão de obra. Sustenta-se, por conseguinte, que essas unidades familiares de produção devem seu sucesso mais à gestão dos recursos tecnológicos empregados no meio produtivo do que propriamente pela dimensão do empreendimento agrícola.

Savoldi e Cunha (2010) acrescentam que, enquanto a grande propriedade se beneficia com o incremento agrícola, em termos de modernização, a pequena propriedade persiste com meios quase que rudimentares de produção, a despeito de receberem o apoio e fomento das políticas agrícolas.

Isso porque a agricultura familiar se funda na relação entre propriedade, trabalho e família e apresenta uma série de particularidades não se restringindo, necessariamente, a uma lógica de subsistência. Sob determinadas situações de escassez, o agricultor pode organizar sua produção visando atender objetivos de sobrevivência.

Como peculiaridades específicas, Médici (2009) destaca que a agricultura familiar não emprega trabalhadores pagos, utilizando o trabalho de seus próprios membros. A quantidade do produto obtida é determinada principalmente pelo tamanho e pela composição da família, pelo número de membros capazes de trabalhar e, além disso, pela produtividade da unidade de trabalho e pela intensidade do esforço dispendido no trabalho durante o ano.

Ainda nas falas do autor acima, percebe-se que a agricultura familiar representa uma associação onde a família, ao mesmo tempo em que é proprietária dos meios de produção, assume o trabalho no estabelecimento produtivo, ou seja, trata-se de uma unidade de produção agrícola onde propriedade e trabalho estão intimamente ligados à família, e a referência à prevenção do meio ambiente se dá justamente pela lógica produtiva ser diferente da realizada em grandes propriedades agrícolas.

Nas propriedades em que se pratica a agricultura familiar, a forma de produção não é padronizada, e é possível associar eficiência, economia e equidade social, elementos característicos daquilo que se considera como determinante na prevenção ambiental, nos moldes do que preconizam a Constituição Federal e a Política Nacional do Meio Ambiente. 
Com isso, são geradas relações harmônicas entre a capacidade de trabalho, a qualidade da terra e a geração de rendas (SANTOS, 2013).

Porém, em termos de efetividade na proteção ao meio ambiente, a agricultura familiar ainda é festejada por poucos, com maior aversão a esse modelo justificado pelo fato de que o aumento da fronteira agrícola no país em relação a esses empreendimentos tem sido o principal responsável pelo desmatamento florestal.

Nesse sentido, medidas e políticas públicas têm sido direcionadas para o atendimento a essa questão. Um exemplo é o Programa de Aquisição de Alimentos (PAA), instaurado em 2003 pela Lei $\mathrm{n}^{\circ} 10.696$, sendo atualmente regido pela Lei $\mathrm{n}^{\circ} 12.512 / 2011$ e Decreto $\mathrm{n}^{\circ}$ 7.775/2012. Operacionalizado pela Companhia Nacional de Abastecimento (CONAB) e pelo Ministério do Desenvolvimento Social (MDS), o PAA atua diretamente nas modalidades de compra com doação simultânea, apoio à formação de estoques pela agricultura familiar, e compra direta da agricultura familiar, o que é conseguido por meio da relação com associações e cooperativas de agricultores familiares (BRASIL, 2011; 2012a).

Apesar de os propósitos do citado PAA possuírem duas missões básicas - a de garantir a comercialização da produção familiar e disponibilizar alimentos para as populações em situação de insegurança alimentar - esse programa tem sido estudado sob a ótica de transformar-se em instrumento de incentivo à regularização ambiental, alterando o sistema agroambiental que atualmente se constata na agricultura familiar brasileira.

No art. 19, inciso I, da citada Lei $n^{\circ} 10.696 / 2003$, descortina-se a presença da questão sustentabilidade entre as finalidades do PAA, bem como nos incisos I e VIII do artigo $2^{\circ}$ do Decreto $\mathrm{n}^{\mathrm{o}}$ 7.775/2012. Nesses dispositivos, é possível perceber que a promoção e a valorização da biodiversidade também passam a ser uma das finalidades do programa (BRASIL, 2011; 2012a).

Na medida em que os produtores orgânicos podem receber até $30 \%$ a mais pelos seus produtos no PAA, pode-se afirmar que esse programa já incentiva a sustentabilidade na agricultura. Entretanto, a sustentabilidade no meio rural não está apenas relacionada ao modo de produção, mas também ao uso adequado da propriedade como um todo, conservando as áreas de preservação permanente e de reserva legal, o que garante a oferta de serviços ambientais.

Em termos de contratação de unidades familiares para o abastecimento do PAA, vale lembrar que, em 2012, o Decreto $\mathrm{n}^{\mathrm{o}} 7.746$ veio a estabelecer critérios, diretrizes e práticas visando à promoção do desenvolvimento nacional sustentável em todas as contratações 
realizadas pela administração pública federal, o que, na prática, corresponde à obrigação de aquisição de bens considerando critérios e práticas de sustentabilidade (BRASIL, 2012b).

\begin{abstract}
Art. 1o Este Decreto regulamenta o art. $3_{-}^{\circ}$ da Lei $\mathrm{n}_{-}^{\mathrm{o}} 8.666$, de 21 de junho de 1993, para estabelecer critérios, práticas e diretrizes gerais para a promoção do desenvolvimento nacional sustentável por meio das contratações realizadas pela administração pública federal direta, autárquica e fundacional e pelas empresas estatais dependentes, e institui a Comissão Interministerial de Sustentabilidade na Administração Pública - CISAP.

Art. 2을 administração pública federal direta, autárquica e fundacional e as empresas estatais dependentes poderão adquirir bens e contratar serviços e obras considerando critérios e práticas de sustentabilidade objetivamente definidos no instrumento convocatório, conforme o disposto neste Decreto (BRASIL, 2012b).
\end{abstract}

São medidas ainda tímidas, mas que contemplam um cenário animador, a despeito de existirem movimentos contrários a esse modelo de desenvolvimento sustentável. A consolidação do modelo de agricultura familiar, no entanto, em sintonia com a proposta de proteção ambiental, far-se-á na medida em que novos avanços tecnológicos estejam disponíveis para os agricultores familiares, permitindo um uso mais racional dos recursos já utilizados nesse segmento.

\title{
6. A AGRICULTURA FAMILIAR E O DIREITO AGRÁRIO
}

Dentro do ordenamento jurídico, o cunho legislativo brasileiro define na Lei 11.326, de 24 de julho de 2006, as diretrizes para a formulação da Política Nacional da Agricultura Familiar e Empreendimentos Familiares. Esta norma parametriza as características norteadora referentes ao agricultor e empreendedor familiar rural, estruturando os devidos efeitos da dinâmica social da agricultura familiar. Nesse sentido, na perspectiva jurídica, estabelece princípios que auxiliam na ordenação das atividades para auxiliar na preservação ambiental e alavancar a economia local. A agricultura familiar torna-se, assim, um agente facilitador que propicia uma melhor articulação para um desenvolvimento de um modelo de agricultura mais adequado na preservação ou recuperação ambiental, coadunado com o progresso estrutural socioeconômica.

Como função social a agricultura familiar configura-se no fato de poder proporcionar os aparatos da estrutura do Estado de Direito Ambiental, as modelações e instrumentação na pavimentação de agregação de valores à proteção do meio ambiente, aliada ao fato gerador e transformador de poder alavancar o desenvolvimento da economia. Logo, tal atividade familiar propicia o fortalecimento de sua função socioeconômica da propriedade, consolidando seu papel na participação e contribuição da produção para o mercado interno 
brasileiro, avançando no apoio de cerca de 8 milhões de jovens que vivem no campo ${ }^{1}$, agregada a importância do cuidado à proteção ambiental, a preservação ao ecossistema. A agricultura familiar se torna assim, o alicerce da auto sustentabilidade relaciona as atividades agropecuárias, no exercício da função social da propriedade e a contribuição a um melhor desenvolvimento sustentável, tornando-se um instrumento de efetividade dos princípios ambientais. Ainda neste entendimento, é salutar observar que estes aparatos que facilitam a existência da agricultura familiar, ressalta o fato do Direito Ambiental não se importar apenas com o meio ambiente, mas com seu principal ambiente do meio, o ser humano em harmonia com o ecossistema. O Direito agrário, enraizado na Constituição Federal, releva a importância da função social da terra, quando em seu artigo 186 declara que:

Art. 186. A função social é cumprida quando a propriedade rural atende, simultaneamente, segundo critérios e graus de exigência estabelecidos em lei, aos seguintes requisitos ${ }^{2}$ :

I - aproveitamento racional e adequado;

II - utilização adequada dos recursos naturais disponíveis e preservação do meio ambiente;

III - observância das disposições que regulam as relações de trabalho;

IV - exploração que favoreça o bem-estar dos proprietários e dos trabalhadores.

Neste sentido, o Direito Agrário, com seu espectro de conjunto de normas que visam regular e organizar as relações da atividade rural, que estabelece parâmetros jurídicos de alcançar alternativas de contribuição a um progresso social e econômico do trabalhador que vive no campo, responsável por alimentar seu país, também visa propiciar aproveitar o solo de forma apropriada, racional, capaz de aumentar o enriquecimento local, da comunidade, e da sociedade, através de uma sadia promoção de valorizar a função social da terra.

\section{CONCLUSÃO}

A agricultura familiar vem ocupando um lugar de destaque no contexto rural, mormente no momento contemporâneo, em que a necessidade populacional em nível mundial clama por atividades produtivas que produzam o mínimo possível de impacto ao meio ambiente.

1 O Governo Federal, através do Ministério da Agricultura, O Plano Nacional de Desenvolvimento Rural Sustentável e Solidário, possui como um de seus desafios estratégicos tornar o campo um lugar atraente para os jovens.

2 A Carta Magna confere à propriedade agrária, um regime jurídico especial, pelo fato da terra ser um bem precioso de produção, capaz de gerar alimentos, riquezas, bem-estar, indispensável à sobrevivência humana em vários aspectos, delineado neste artigo 186 que indica que a função social da propriedade agrária é constituída por: um fator econômico, um fator ambiental e um social. 
Ao mesmo tempo, a agricultura familiar se sustenta em um modelo preservacionista, que, a despeito de não conferir uma progressiva geração de trabalho e renda em níveis maximizados, ao menos confere a possibilidade de produção agrícola sem a necessidade de desmatamento de extensas áreas, o que, por si, já denota seu caráter de proteção ao meio ambiente.

Nesse sentido, e levando-se em conta o apelo ao desenvolvimento sustentável, calcado na proteção ao meio ambiente, considera-se que a agricultura familiar representa um modelo preservacionista, garantindo sustentabilidade, viabilidade econômica e equidade social, tendose, por conseguinte, respondido ao objetivo geral da pesquisa e sua problemática norteadora.

Sugere-se, no entanto, que estudos mais avançados sejam configurados e aplicados, aproveitando-se o momento atual, em que a agricultura familiar desponta como uma das grandes responsáveis pelo abastecimento nacional, pelo efeito comercialização de excedentes.

\section{REFERÊNCIAS}

ALTIERI, M. Agroecologia: a dinâmica produtiva da agricultura sustentável. $2^{\mathrm{a}}$ ed. Porto Alegre: Ed. Universidade, 2000.

BENJAMIN, A. H. V. Responsabilidade civil pelo dano ambiental. Revista de Direito Ambiental. n. 9, p. 36. São Paulo: Revista dos Tribunais, 1998. Constitucionalização do ambiente e ecologização da Constituição brasileira. São Paulo: Saraiva, 2008.

BICALHO. A. M. S. M. Desenvolvimento rural sustentável e geografia agrária. In: XII Encontro Nacional de Geografia Agrária, Anais.... 8 ago. 1998.

BRASIL. Câmara dos Deputados. Centro de Documentação e Informação. Constituição da República Federativa do Brasil. Brasília: 1988.

Lei $n^{\circ}$ 12.512, de 14 de outubro de 2011. Institui o Programa de Apoio à Conservação Ambiental e o Programa de Fomento às Atividades Produtivas Rurais; altera as Leis $n^{\circ}$ s 10.696, de 2 de julho de 2003, 10.836, de 9 de janeiro de 2004, e 11.326, de 24 de julho de 2006. Brasília: DOU, 2011.

Decreto n $\mathbf{n}^{\mathbf{7}}$ 7.775, de 4 de julho de 2012. Regulamenta o art. 19 da $\overline{\text { Lei }{ }^{\circ}} 10.696$, de 2 de julho de 2003, que institui o Programa de Aquisição de Alimentos, e o Capítulo III da Lei $\mathrm{n}^{\circ}$ 12.512, de 14 de outubro de 2011, e dá outras providências. Brasília: DOU, 2012a.

. Presidência da República. Casa Civil. Subchefia para Assuntos Jurídicos. Lei no 6.938, de 31 de agosto de 1981. Dispõe sobre a Política Nacional do Meio Ambiente, seus fins e mecanismos de formulação e aplicação, e dá outras providências. Brasília: DOU, 1981. 
Decreto $\mathrm{n}^{\circ}$ 1.946, de 28 de junho de 1996. Cria o

Programa Nacional de Fortalecimento da Agricultura Familiar - PRONAF, e dá outras providências. Brasília: DOU, 1996.

$\overline{\text { Civil. Brasília: DOU, } 2002 .}$

Lei $\mathbf{n}^{0}$ 10.406, de 10 de janeiro de 2002. Institui o Código

Lei $n^{0}$ 11.326, de 24 de julho de 2006. Estabelece

as diretrizes para a formulação da Política Nacional da Agricultura Familiar e Empreendimentos Familiares Rurais. Brasília: DOU, 2006.

Decreto $\mathrm{n}^{\mathbf{0}}$ 7.746, de 5 de junho de 2012. Regulamenta o

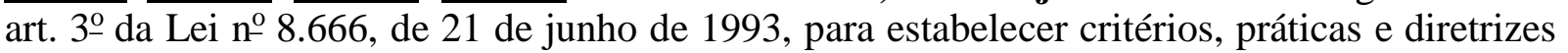
para a promoção do desenvolvimento nacional sustentável nas contratações realizadas pela administração pública federal, e institui a Comissão Interministerial de Sustentabilidade na Administração Pública - CISAP. Brasília: DOU, 2012b.

BUAINAIN, A. M.; ROMEIRO, A. R.; GUANZIROLI, C. Agricultura familiar e o novo mundo rural. Sociologias, Porto Alegre, ano 5, n 10, p. 312-47, jul. /dez. 2003.

CARMO, M. S. A produção familiar como locus ideal da agricultura sustentável. In: FERREIRA, Ângela D. D., BRANDENBURG, Alfio (Org.). Para pensar outra agricultura. Curitiba: ed. UFPR, 1998.

CAVALCANTI, C. Sustentabilidade da economia: paradigmas alternativos da realização econômica. In: CAVALCANTI, C. (Org.). Desenvolvimento e natureza: estudo para uma sociedade sustentável. São Paulo: Cortez; Recife, PE: Fundação Joaquim Nabuco. 1998.

COSTA, M. P. B. Agroecologia: uma alternativa viável às áreas reformadas e à produção familiar, Reforma Agrária, v. 23, n. 1, p. 53-69, jan. /abr. 2003.

COUTINHO, M. R. A. Desenvolvimento sustentável da agricultura. EcoDebate Cidadania \& Meio Ambiente. 3 ago. 2011. Disponível em: <http://www.ecodebate.com.br/2011/08/03/desenvolvimento-sustentavel-da-agriculturaartigo-de-antonio-mario-reis-de-azevedo-coutinho/> Acesso em 18 mar. 2016.

CRUZ, F. T. Produtores, consumidores e valorização de produtos tradicionais: um estudo sobre qualidade de alimentos a partir do caso do queijo serrano dos Campos de Cima da Serra - RS. Tese (Doutorado em Desenvolvimento Rural). Faculdade de Ciências Econômicas. Universidade Federal do Rio Grande do Sul. Porto Alegre: 2012.

DAMACENA, F. D. L. A defesa do meio ambiente como princípio da ordem econômica. Âmbito Jurídico, Rio Grande, XII, n. 66, jul. 2009. Disponível em: <http://www.ambitojuridico.com.br/site/index.php?n_link=revista_artigos_leitura> Acesso em mar 2016.

DELGADO, N. G. Agronegócio e agricultura familiar no Brasil: desafios para a transformação democrática do meio rural. Novos Cadernos NAEA, v. 15, n. 1, p. 85-129, jun. 2012.

EHLERS, E. M. O que se entende por agricultura sustentável? In: VEIGA, J. E. (Org). Ciência Ambiental: primeiros mestrados. São Paulo: Annablume: FAPESP. 2008. 
FARIAS, T. Q. Princípios gerais do direito ambiental. Âmbito Jurídico, Rio Grande, IX, n. 35, $\operatorname{dez} 2006 . \quad$ Disponível em: <http://www.ambitojuridico.com.br/site/index.php?n_link=revista_artigos_leitura\&artigo_id=1543>. Acesso em mar 2016.

FAUTH, E. M. Agricultura familiar: força revigorada. Indicadores Econômicos FEE, Porto Alegre, v. 34, n; 3, p. 25-34, dez. 2006.

FREITAS, G. P. A tutela penal do meio ambiente. In: Dano ambiental, prevenção, reparação e repressão, São Paulo: Revista dos Tribunais, 2003.

GERMER, C. M. A irrelevância prática da agricultura "familiar" para o emprego agrícola. 2014. Disponível em: <www.coptec.org.br/.../Claus\%20Germer\%20\%20Irrelevância\%20Agric> Acesso em: 18 mar. 2016.

GLIESSMAN, S. R. Agroecologia: processos ecológicos em agricultura sustentável. Porto Alegre: Ed. Universidade/UFRGS, 2000.

GOMES, I. Sustentabilidade social e ambiental na agricultura familiar. Revista de Biologia e Ciências da Terra, v. 5, n. 1, 2004.

LEHFELD, L. S.; CARVALHO, N. C. B.; BALBIM, L. I. N. Código Florestal comentado e anotado: artigo por artigo. 2. ed. rev. e atual. São Paulo: Método, 2013.

; MENDONÇA, M. R. G.; NASCIMENTO JUNIOR, V. F. Agricultura familiar como instrumento de desenvolvimento do Estado de Direito Ambiental. 2014. Disponível em: $\quad<$ http://genjuridico.com.br/2014/11/12/agricultura-familiar-como-instrumento-dedesenvolvimento-do-estado-de-direito-ambiental/> Acesso em: 25 mar. 2016.

MACHADO, P. A. L. Direito Ambiental Brasileiro. 9. ed. São Paulo: Revista dos Tribunais, 2001

Estudos de Direito Ambiental. São Paulo, Malheiros Editores, 2004.

MATTEI, L. Políticas públicas de apoio à agricultura familiar: o caso recente do PRONAF no Brasil. Raízes, v. 35, n. 1, p. 6-29, jan../jun. 2015.

MÉDICI, A. Família na agricultura: indivíduos, projetos, pequena empresa e competitividade.

Revista Ciência em Extensão, v. 5, n. 2, p. 60-72, 2009.

MILARÉ, E. Direito do Ambiente. 3. ed., São Paulo: Revista dos Tribunais, 2003.

MIRRA, A. L. V. Princípios fundamentais do Direito Ambiental. Revista de Direito Ambiental. n. 2, 1996.

OliVEIRA, N. D. A.; AlEIXO, A. D.; SATO, S. A. S.; BElEtE, N. A. S.; HABITZREUTER, P. B. Práticas produtivas da agricultura familiar: um estudo no Município de Espigão D’Oeste (RO). XXXV Encontro Nacional de Engenharia de Produção. Anais..., Fortaleza, 13 a 16 out. 2015. 
OTANI, M. N. et al. Caracterização e estudo da agricultura familiar: o caso dos produtores de leite do município de Lagoinha, Estado de São Paulo. Informações Econômicas, São Paulo: v. 31, n. 4, abr. 2001.

RAMID, J.; RIBEIRO. A. Declaração do Rio de Janeiro. Estudos Avançados, v. 6, n. 15, p. 153-9, 1992.

REIS, C. S. A função social da propriedade rural e o acesso à terra como respeito à dignidade da pessoa humana. Âmbito Jurídico, Rio Grande, XI, n. 53, maio 2008. Disponível em: <http://www.ambito-juridico.com.br/site/index.php?n_link=revistas>. Acesso em 18 mar 2016.

RODRIGUES, M. A. Elementos de direito ambiental: Parte Geral. 2. ed. São Paulo: Editora Revista dos Tribunais, 2005.

ROMEIRO, A. R. Meio ambiente e dinâmica de inovações na agricultura. São Paulo: Annablume. FAPESP. 1998.

ROSA, S. L. C. Agricultura familiar e desenvolvimento local sustentável. $37^{\circ}$ Congresso Brasileiro de Economia e Sociologia Rural, Anais..., Foz do Iguaçu, ago. 1999.

SANTOS, C. F. Diagnóstico da agricultura familiar no munício de Janduí/RN: perspectiva social, econômica e ambiental. Dissertação (Mestrado em Ambiente, Tecnologia e Sociedade). Universidade Federal Rural do Semi-Árido. Mossoró: 2013.

SANTILLI, J. Socioambientalismo e novos direitos. São Paulo: Editora Petrópolis/ISA/IEB, 2005.

SAVOLDI, A.; CUNHA, L. A. Uma abordagem sobre a agricultura familiar, PRONAF e a modernização da agricultura no sudoeste do Paraná na década de 1970. Revista Geografar, Curitiba, v. 5, n. 1, p. 25-45, jan. /jun. 2010.

SEBRAE-Serviço Brasileiro de Apoio às Micro e Pequenas Empresas. Agricultura familiar: um bom negócio para o desenvolvimento local. Brasília: SEBRAE, 2014.

SILVA, J. A. Direito Ambiental Constitucional. 4. ed. São Paulo: Malheiros, 2003.

VEIGA, J. E. Problemas da transição à agricultura sustentável. Estudos Econômicos. São Paulo: v. 24, n. especial, p. 9-29, 2004.

WANDERLEY, N. Raízes históricas do campesinato brasileiro. In: TEDESCO (Org.) Agricultura familiar: realidades e perspectivas. Passo Fundo-RS: UPF, 2001.

http://www2.camara.leg.br/legin/fed/decret/1996/decreto-1946-28-junho-1996-435815-

publicacaooriginal-1-pe.html 